\title{
Electrodeposition Fabrication of Pd Nanoparticles on Glassy Carbon Electrode Towards Methanol Oxidation Application
}

\author{
${ }^{1}$ Guohui Chang, ${ }^{1}$ Yonglan Luo, ${ }^{1}$ Wenbo Lu, ${ }^{1}$ Xiaoyun Qin, \\ ${ }^{1,3}$ Abdullah Mohamed Asiri, ${ }^{1,3}$ Abdulrahman Obaid Al-Youbi and ${ }^{1,2,3}$ Xuping Sun \\ ${ }^{1}$ Chemical Synthesis and Pollution Control Key Laboratory of Sichuan Province, \\ Faculty of Chemistry and Chemical Industry, China West Normal University, Nanchong 637002, Sichuan, China \\ ${ }^{2}$ Department of Chemistry, Faculty of Science, King Abdulaziz University, Jeddah 21589, Saudi Arabia \\ ${ }^{3}$ Department of Chemistry, Center of Excellence for Advanced Materials Research, \\ Faculty of Science, King Abdulaziz University, Jeddah 21589, Saudi Arabia
}

Received 2012-06-29, Revised 2013-01-04; Accepted 2013-04-12

\begin{abstract}
The present paper reports on the rapid fabrication of Pd nanoparticles on glassy carbon electrode by eletrodeposition technique. It suggests that such film exhibits good catalytic activity and stability with respect to methanol oxidation in an alkaline media. It also suggests that the loading of the Pd nanoparticles on the substrate and therefore the effective catalytic area can be tuned by the deposition time used.
\end{abstract}

Keywords: Fuel Cell, Methanol Oxidation, Pd Nanoparticle, Stable Film, Electrodeposition

\section{INTRODUCTION}

Nanostructures exhibit quite unique properties which are quite different from their bulk counterparts and therefore, their synthesis has always been a hot research topic (Burda et al., 2005). Indeed, the past years have witnessed the rapid development of synthetic methods of all kinds of nanostructures (Cushing et al., 2004; Watanabe et al., 2006). Among such nanostructures, gold nanostructures are the most stable and hold great promise as key materials and building block in the $21 \mathrm{st}$ century (Daniel and Astruc, 2004) and represent one of the most widely studied nanomaterials so far (Hayat, 1989). It is well-documented that nanoparticles-modified electrodes can exhibit several unique advantages over conventional macroelectrodes such as enhancement of mass transport, catalysis, high effective surface area and control over electrode microenvironment (Katz et al., 2004). Electrodeposition-based cost-effective fabrication of nanoparticles-modified electrodes has been paid much attention due to its unique properties, such as the requirement of simple instrumentation, the easy control of both the size and morphology of the as-deposited nanostructures through adjusting the electrochemical parameters (Yu et al., 2007).

Direct Methanol Fuel Cells (DMFCs) are intensively studied and considered as possible power sources for electric vehicles and other portable applications in the near future (Chen and Yang, 2003; Wang et al., 2004). The anodic oxidation of methanol on electrode surfaces in acidic medium is a catalytic reaction, giving $\mathrm{CO}_{2}$ and six electrons. The main factors limiting the practical application of DMFC are the sluggish kinetics of methanol electrooxidation at anode and the poisoning of electrode surfaces. As a result, the development of highly effective methanol electrooxidation catalysts has been paid much attention. Pt exhibits good electrocatalytic performance with respect to the methanol electrooxidation and hence Pt-based nanoparticles are

\footnotetext{
Corresponding Author: Guohui Chang, Chemical Synthesis and Pollution Control Key Laboratory of Sichuan Province, Faculty of Chemistry and Chemical Industry, China West Normal University, Nanchong 637002, Sichuan, China
} 
intensively used as a catalyst for applications in DMFC (Hsu et al., 2010), but its high cost and limited supply of Pt constitute a major barrier to the development of DMFC. It is therefore highly desirable to develop lowcost non-Pt electrocatalysts with comparable or improved kinetics for methanol oxidation. Indeed, many non-Pt metals have recently been investigated (Jafarian et al., 2006; Heli et al., 2004). Among such metals, Pd is a good electrocatalyst for methanol in alkaline solution (Xu et al., 2007a; 2007b; Singh et al., 2009) and its abundance is at least fifty times more than that of $\mathrm{Pt}$ on earth (Liu et al., 2007; 2009). In addition, Ha et al. (2005) have demonstrated that $\mathrm{Pd}$ and $\mathrm{Pd} / \mathrm{C}$ catalysts can overcome the CO-poisoning effect and thus lead to high performance in DMFCs. On the other hand, catalyst support is considered as an important factor that influences its activity. Researchers have found that carbon materials can improve the activity and stability of the catalysts employed in fuel cells (Yoo et al., 2008; Bessel et al., 2001; Joo et al., 2006; Bang et al., 2007; Xu et al., 2008; Zhao et al., 2010; Serp et al., 2003; Dong et al., 2010). However, above methods have their inherent drawbacks, such as the pre-synthesis of nanoparticles of catalysts and the modification of both the carbon substrates and the nanoparticles to effectively immobilize the nanoparticles on the substrates. The present paper demonstrates the use of electrodeposition technique to the rapid fabrication of Pd nanoparticles on bare Glassy Carbon Electrode (GCE) surface. It suggests that such film exhibits good catalytic activity and stability for the electrooxidation of methanol. It also suggests that the loading of the Pd nanoparticles on the substrate and therefore the effective catalytic area can be tuned by the deposition time used.

\section{MATERIALS AND METHODS}

$\mathrm{H}_{2} \mathrm{PdCl}_{4}, \quad \mathrm{H}_{2} \mathrm{SO}_{4}, \quad \mathrm{HCl}, \quad \mathrm{NaOH}, \quad \mathrm{CH}_{3} \mathrm{OH}$ were purchased from Aladdin Reagent Database Inc. (Shanghai, China) and used as received without further purification. All aqueous solutions were made with double-distilled water. Electrodeposition was carried out with a CHI660D electrochemical workstation (Shanghai, China) in a three electrode cell, with the use of a $\mathrm{Ag} / \mathrm{AgCl}$ (saturated $\mathrm{KCl}$ ) as reference electrode, a platinum coil as auxiliary electrode and a Glassy Carbon (GC) disk electrode (3 $\mathrm{mm}$ in diameter) as the working electrode. All electrochemical measurements were performed in a conventional three-electrode cell. Scanning Electron Microscopy (SEM) was made on a JSM6330F (JEOL, Japan).
The GCE was pretreated using the following process. First, the surface of a GCE was polished with 1.0 and 0.3 $\mu \mathrm{m} \alpha$-alumina powders in sequence, rinsed thoroughly with twice distilled water and placed in a water-filled ultrasonic bath over a $2 \mathrm{~min}$ period. After dried in air, $\mathrm{Pd}$ nanoparticles was grown on the GCE by electrodeposition in a solution containing $5 \mathrm{mM} \mathrm{H}_{2} \mathrm{PdCl}_{4}$ and $0.5 \mathrm{M} \mathrm{HCl}$ at $-0.2 \mathrm{~V}$ (vs $\mathrm{Ag} / \mathrm{AgCl}$ ) over a $200 \mathrm{~s}$ period (the resulting Pd nanoparticles-supported GCE is denoted as $\mathrm{Pd} / \mathrm{GCE})$. After the electrodeposition, the modified electrodes were rinsed twice in water and air-dried at room temperature for characterization and further use.

\section{RESULTS}

Figure 1 shows typical SEM image of as-prepared Pd structures, indicating the GCE substrate is covered by flower-like Pd structures with diameters in the range of $300-500 \mathrm{~nm}$. A local view of one Pd flower (inset) further reveals the $\mathrm{Pd}$ structure consists of small nanoparticles. It is worthwhile mentioning that such Pd flowers exhibit no observable change on the substrate after it is subjected to a sonication process for several minutes, indicating that the Pd flowers are very stable (Xu et al., 2007a; 2007b; Singh et al., 2009).

Figure 2 shows CV curves of the Pd/GCE in a $0.5 \mathrm{M}$ $\mathrm{NaOH}$ solution at $0.05 \mathrm{~V} / \mathrm{s}$. The Pd electrodeposition was performed in solution containing $5 \mathrm{mM} \mathrm{H}_{2} \mathrm{PdCl}_{4}$ and 0.5 $\mathrm{M} \mathrm{HCl}$ at- $0.2 \mathrm{~V}$ over a period of time of 0, 50, 100200 , 400 and $800 \mathrm{~s}$. The appearances of well-defined feature peaks of $\mathrm{Pd}$ electrodes corresponding to hydrogen adsorption-desorption at-0.1-0 $\mathrm{V}$, below- $0.1 \mathrm{~V}$ is hydrogen absorption and evolution and palladium-oxide formation at $0.6-1.2 \mathrm{~V}$ and reduction at $0.46 \mathrm{~V}$, demonstrating the successful deposition of Pd on GCE.

Figure 3 and 4 shows $C V$ curves of the $\mathrm{Pd} / \mathrm{GCE}$ in a $0.5 \mathrm{M} \mathrm{NaOH}$ solution at $0.05 \mathrm{~V} / \mathrm{s}$ in the presence of 1.0 $\mathrm{M} \mathrm{CH}_{3} \mathrm{OH}$. The Pd electrodeposition was performed in solution containing $5 \mathrm{mM} \mathrm{H}_{2} \mathrm{PdCl}_{4}$ and $0.5 \mathrm{M} \mathrm{HCl}$ at- 0.2 $\mathrm{V}$ over a period of time of $0,50,100,200,400$ and 800 s. It is clearly observed that the peak currents of both the forward and reverse CV scan increase with increase in the deposition time, which can be attributed to that increased deposition time leads to more Pd nanoparticles on GCE surface and hence larger effective catalytic area of $\mathrm{Pd}$ as well as higher catalytic current, that is, deposition time can exert good control over the formation of Pd nanoparticles on the electrode surface. 


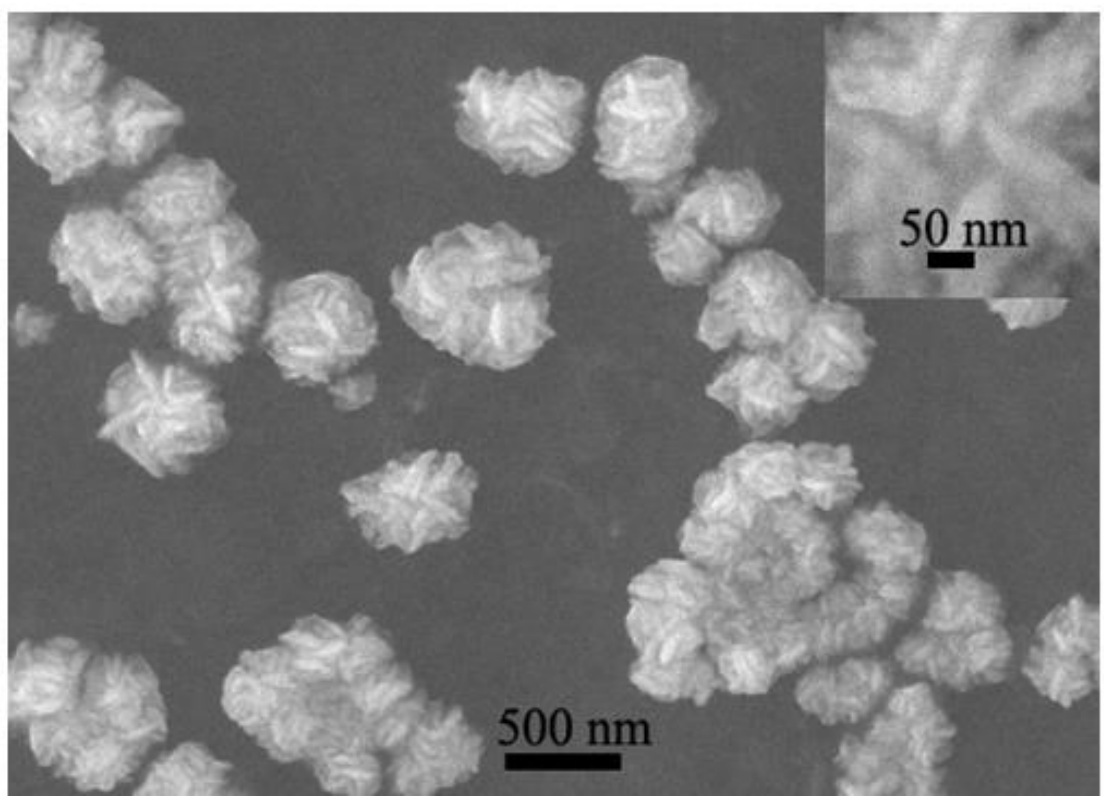

Fig. 1. Typical SEM image of the Pd structures electrodeposited on GCE in a solution containing $5 \mathrm{mM} \mathrm{H}_{2} \mathrm{PdCl}_{6}$ and $0.5 \mathrm{M}$ HCL at $0.2 \mathrm{~V}$ over a 200 -s period. Inset shows the local view of one Pd flower

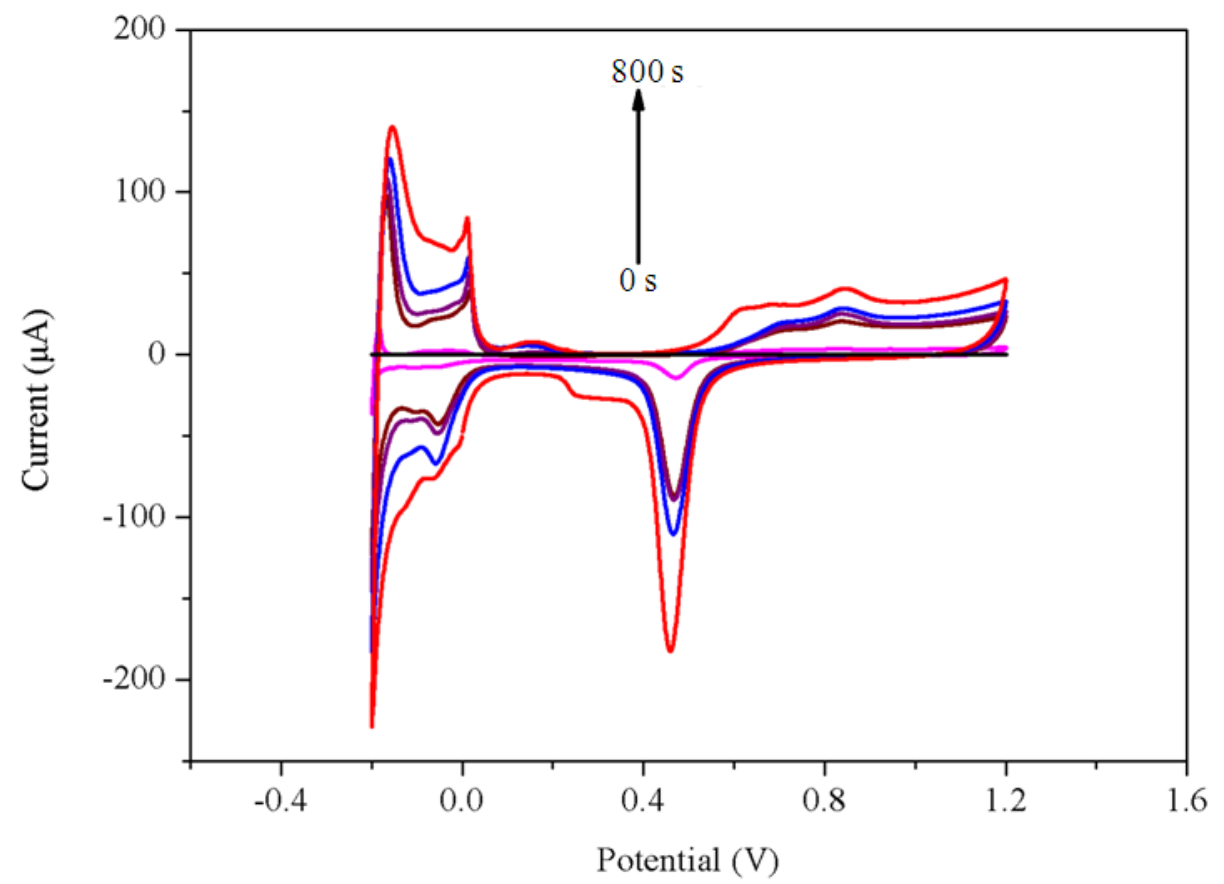

Fig. 2. Cyclic voltammetry (CV) curves of the Pd/GCE in a $0.5 \mathrm{M} \mathrm{NaOH}$ solution at $0.05 \mathrm{~V} / \mathrm{s}$. The Pd electrodeposition was performed in solution containing $5 \mathrm{mM} \mathrm{H}_{2} \mathrm{PdCl}_{4}$ and $0.5 \mathrm{M} \mathrm{HCl}$ at $-0.2 \mathrm{~V}$ over a period of time of $0,50,100200,400$ and $800 \mathrm{~s}$ 
Guohui Chang et al. / American Journal of Nanotechnology, 4 (1): 1-7, 2013

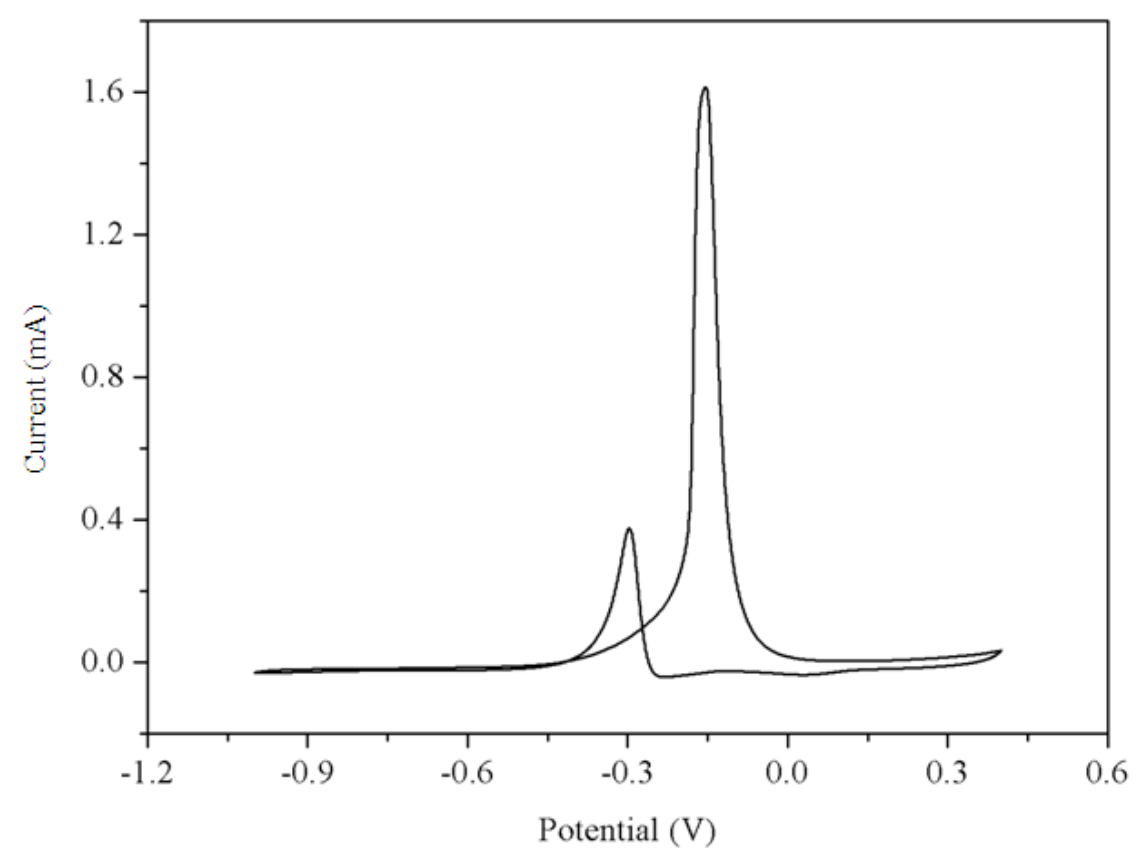

Fig. 3. $\mathrm{CV}$ curve of the $\mathrm{Pd} / \mathrm{GCE}$ at $0.05 \mathrm{~V} / \mathrm{s}$ in a $0.5 \mathrm{M} \mathrm{NaOH}$ solution in the presence of $1.0 \mathrm{M} \mathrm{CH}_{3} \mathrm{OH}$. The Pd electrodeposition was performed in solution containing $5 \mathrm{mM} \mathrm{H}_{2} \mathrm{PdCl}_{4}$ and $0.5 \mathrm{M} \mathrm{HCl}$ at $-0.2 \mathrm{~V}$ for $200 \mathrm{~s}$

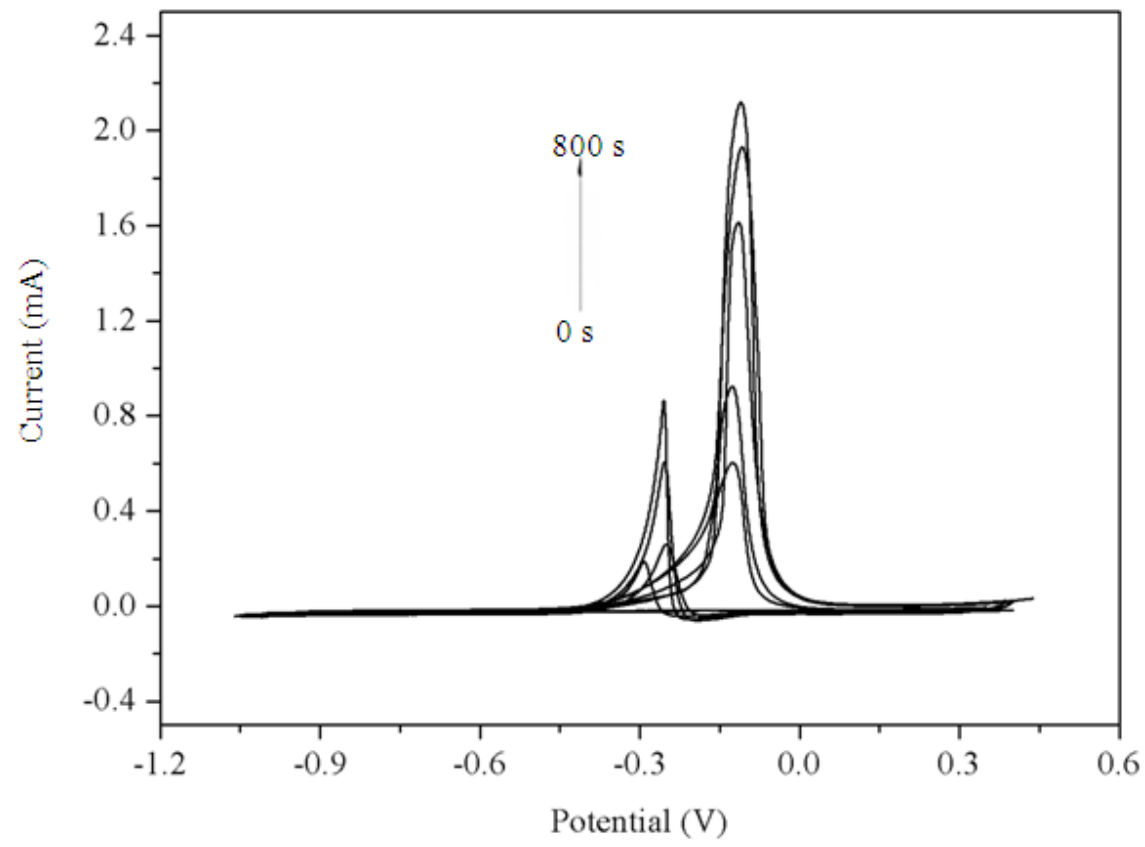

Fig. 4. $\mathrm{CV}$ curves of the $\mathrm{Pd} / \mathrm{GCE}$ in a $0.5 \mathrm{M} \mathrm{NaOH}$ solution at $0.05 \mathrm{~V} / \mathrm{s}$ in the presence of $1.0 \mathrm{M} \mathrm{CH} \mathrm{CH}_{3} \mathrm{OH}$ The $\mathrm{Pd}$ electrodeposition was performed in solution containing $5 \mathrm{mM} \mathrm{H}_{2} \mathrm{PdCl}_{4}$ and $0.5 \mathrm{M} \mathrm{HCl}$ at $-0.2 \mathrm{~V}$ over a period of time of $0,50,100,200,400,800 \mathrm{~s}$ 


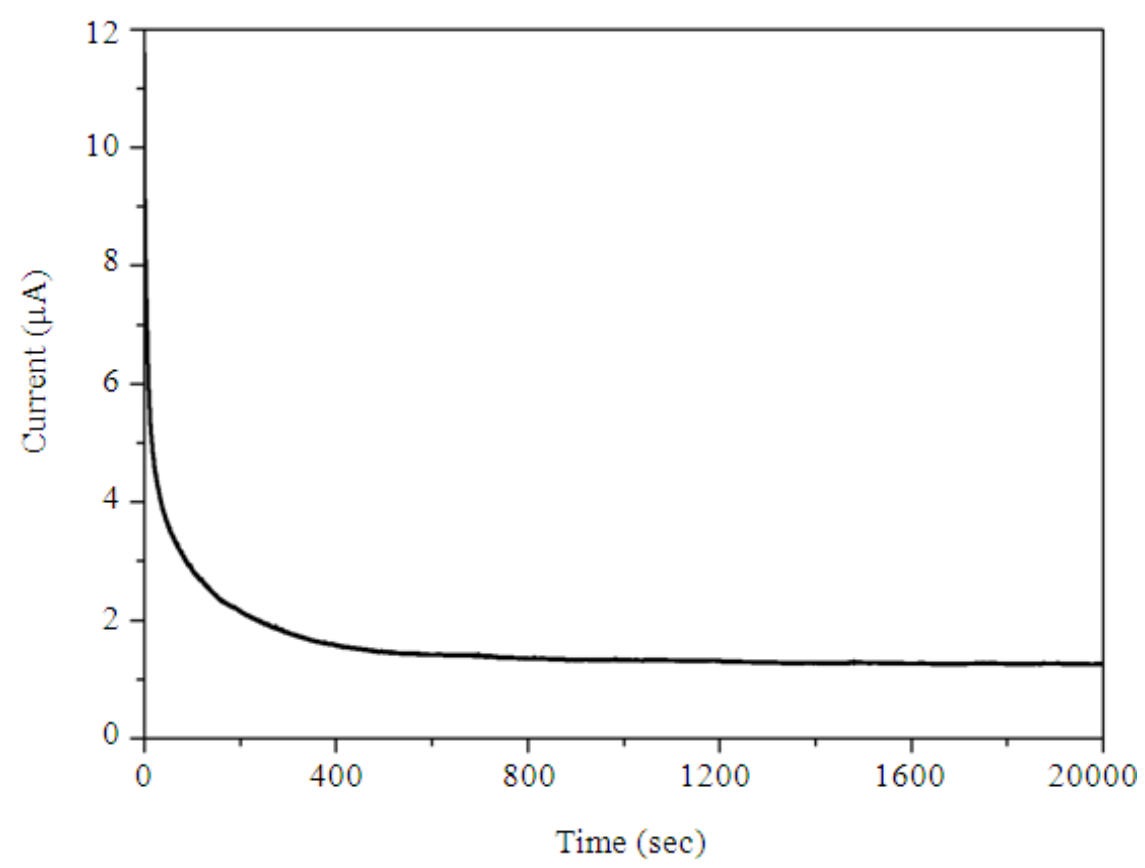

Fig. 5. Chronoamperometry of $\mathrm{Pd} / \mathrm{GCE}$ in $0.5 \mathrm{M} \mathrm{NaOH}+1 \mathrm{M} \mathrm{CH}_{3} \mathrm{OH}$ at an constant potential of $-0.1 \mathrm{~V}$ at $25^{\circ} \mathrm{C}$

It is well known that the stability of catalysts is important for the application of fuel cell. So the longterm stability of the catalytic performance was then investigated by chronoamperometric measurements where the current density-time (I-t) curves at constant potentials were recorded (Chen and Chen, 2011). Fig. 5 shows the chronoamperometric curves of Pd/GCE in 0.5 $\mathrm{M} \mathrm{NaOH}+1 \mathrm{M} \mathrm{CH}_{3} \mathrm{OH}$ at an applied potential of $-0.1 \mathrm{~V}$ over $2000 \mathrm{~s}$ period. The rapid current decay in the first $100 \mathrm{~s}$ showed the poisoning of the electrocatalysts, likely due to the formation of intermediate and some poisoning species during the methanol oxidation reaction (Zhao et al., 2011). With the poisoning of COlike intermediates, the current density decayed in the first $400 \mathrm{~s}$ and attained a steady state thereafter, indicating that these Pd flowers form very stable film on GCE surface and also exhibit stable catalytic performance towards methanol oxidation.

\section{DISCUSSION}

It can be seen that the peak currents increase with increase in the deposition time, suggesting the loading of Pd on GCE can be simply controlled by varying the deposition time. By means of the reduction chemisorbed oxygen methods and CV (Grigoriev et al., 2008; Korovin, 1976), the Electrochemical Active Surface area (EAS) of Pd with different electrodeposition time ranging from 0 $800 \mathrm{~s}$ can be calculated by the following calculation Equation 1 (Nikiforova et al., 2010):

$\mathrm{EAS}=\frac{\mathrm{Q}_{\mathrm{O}}}{0.42}$

where, $\mathrm{Q}_{0}(\mathrm{mC})$ is the quantity of electricity spent for removal of a monolayer of atomic oxygen adsorbed on the Pd surface, $0.42 \mathrm{mC}$ is the quantity of electricity consumed for an oxygen monolayer formation on a surface area of $1 \mathrm{~cm}^{2}$. The EAS of Pd with different electrodeposition time ranging from $0-800 \mathrm{~s}$ are thus determined to be $0,1.141 \mathrm{~cm}^{2}, 1.283 \mathrm{~cm}^{2}, 1.347 \mathrm{~cm}^{2}$, $1.87 \mathrm{~cm}^{2}$, respectively.

It is also established that the ratio of the forward anodic peak current density $\left(\mathrm{I}_{\mathrm{F}}\right)$ to the reverse anodic peak current density $\left(I_{R}\right)$ can be used to describe the catalyst tolerance to $\mathrm{CO}$ and other carbonaceous species. In our present study, it is seen that the onset of methanol oxidation peak is about- $0.50 \mathrm{~V}$ and the peak potential position is at about $-0.15 \mathrm{~V}$ in the forward scan. Another oxidation peak in the reverse scan is observed at about $0.29 \mathrm{~V}$. The corresponding ratio of $\mathrm{I}_{\mathrm{F}} / \mathrm{I}_{\mathrm{R}}$ is measured to be 
about 3.9, which is higher than the Pd-modified macroporous $\mathrm{Pt}$ (the $\mathrm{I}_{\mathrm{F}} / \mathrm{I}_{\mathrm{R}}$ value is 1.18) and the $\mathrm{Pd}$ nanoparticles supported on 2-Aminophenoxazin-3-one (APZ) functionalized multi-walled carbon nanotubes (Pd/APZ-MWCNTs) (Du et al., 2009; Xu et al., 2007a) (the $I_{F} / I_{R}$ value is 1.93 ). It suggests that the Pd film thus formed generates a high complete oxidation of methanol to carbon dioxide. Above observations indicate that GCE-supported Pd film could serve as an ideal candidate for direct methanol fuel cell electrodes.

\section{CONCLUSION}

In summary, electrodeposition has been proven to be an effective method for the rapid fabrication of film of $\mathrm{Pd}$ nanoparticles on bare glassy carbon electrode. The resulting film is stable and exhibits good catalytic activity with respect to methanol oxidation in an alkaline media. The loading of the Pd nanoparticles on the substrate can be rationally controlled by the deposition time. Such Pd film may find application in direct methanol fuel cell.

\section{REFERENCES}

Bang, J.H., K. Han, S.E. Skrabalak, H. Kim and K.S. Suslik, 2007. Porous carbon supports prepared by ultrasonic spray pyrolysis for direct methanol fuel cell electrodes. J. Phys. Chem. C, 111: 10959-10964. DOI: $10.1021 / \mathrm{jp} 071624 \mathrm{v}$

Bessel, C.A., K. Laubernds, N.M. Rodriguez and R.T.K. Baker, 2001. Graphite nanofibers as an electrode for fuel cell applications. J. Phys. Chem. B, 105: 11151118. DOI: $10.1021 / \mathrm{jp} 003280 \mathrm{~d}$

Burda, C., X. Chen, R. Narayanan and M.A. El-Sayed, 2005. Chemistry and properties of nanocrystals of different shapes. Chem. Rev., 105: 1025-1102. DOI: $10.1021 / \mathrm{cr} 030063 \mathrm{a}$

Chen, C.Y. and P. Yang, 2003. Performance of an airbreathing direct methanol fuel cell. J. Power Sources, 123: 37-42. DOI: 10.1016/S03787753(03)00434-8

Chen, W. and S. Chen, 2011. Iridium-platinum alloy nanoparticles: Composition-dependent electrocatalytic activity for formic acid oxidation. J. Mater. Chem., 21: 9169-9178. DOI: 10.1039/C1JM00077B

Cushing, B.L., V.L. Kolesnichenko and C.J. O'Connor, 2004. Recent advances in the liquid-phase syntheses of inorganic nanoparticles. Chem. Rev., 104: $3893-$ 3946. DOI: $10.1021 / \mathrm{cr} 030027 \mathrm{~b}$
Daniel, M.C. and D. Astruc, 2004. Gold Nanoparticles: Assembly, supramolecular chemistry, quantum-sizerelated properties and applications toward biology, catalysis and nanotechnology. Chem. Rev., 104: 293-346. DOI: 10.1021/cr030698+

Dong, L., R.R.S. Gari, Z. Li, M.M. Craig and S. Hou, 2010. Graphene-supported platinum and platinumruthenium nanoparticles with high electrocatalytic activity for methanol and ethanol oxidation. Carbon, 48: 781-787. DOI: 10.1016/j.carbon.2009.10.027

Du, Y., K. Lv, B. Su, N. Zhang and C. Wang, 2009. Electro-reduction of oxygen and electro-oxidation of methanol at Pd monolayer-modified macroporous $\mathrm{Pt}$ electrode. J. Appl. Electrochem., 39: 2409-2414. DOI: $10.1007 / \mathrm{s} 10800-009-9928-9$

Grigoriev, S.A., P. Millet and V.N. Fateev, 2008. Evaluation of carbon-supported $\mathrm{Pt}$ and $\mathrm{Pd}$ nanoparticles for the hydrogen evolution reaction in PEM water electrolysers. J. Power Sources, 177: 281-285. DOI: 10.1016/j.jpowsour.2007.11.072

Ha, S., R. Larsen and R.I. Masel, 2005. Performance characterization of $\mathrm{Pd} / \mathrm{C}$ nanocatalyst for direct formic acid fuel cells. J. Power Sources, 144: 28-34. DOI: 10.1016/j.jpowsour.2004.12.031

Hayat, M.A., 1989. Colloidal Gold: Principles, Methods and Applications. 1st Edn., Academic Press, San Diego, ISBN-10: 0123339278, pp: 536.

Heli, H., M. Jafarian, M.G. Mahjani and F. Gobal, 2004. Electro-oxidation of methanol on copper in alkaline solution. Electrochim. Acta, 49: 4999-5006. DOI: 10.1016/j.electacta.2004.06.015

Hsu, C.H., H.Y. Liao and P.L. Kuo, 2010. Aniline as a dispersant and stabilizer for the preparation of $\mathrm{Pt}$ nanoparticles deposited on carbon nanotubes. J. Phys. Chem. C, 114: 7933-7939. DOI: 10.1021/jp100328f

Jafarian, M., R.B. Moghaddam, M.G. Mahjani and F. Gobal, 2006. electro-catalytic oxidation of methanol on a $\mathrm{Ni}-\mathrm{Cu}$ alloy in alkaline medium. J. Applied Electrochem., 36: 913-918. DOI: 10.1007/s10800006-9155-6

Joo, S.H., C. Pak, D.J. You, S.A. Lee and H.I. Lee et al., 2006. Ordered Mesoporous Carbons (OMC) as supports of electrocatalysts for Direct Methanol Fuel Cells (DMFC): Effect of carbon precursors of OMC on DMFC performances. Electrochim. Acta, 52: 1618-1626. DOI: 10.1016/j.electacta.2006.03.092 
Katz, E., I. Willner and J. Wang, 2004. Electroanalytical and bioelectroanalytical systems based on metal and semiconductor nanoparticles. Electroanalysis, 16: 19-44. DOI: 10.1002/elan.200302930

Korovin, V.A., 1976. Metabolic rate of the underyearling of the carp, Cyprinus carpio, adapted to different water temperatures. J. Ichtyol., 6: 168-172.

Liu, J., J. Ye, C. Xu, S.P. Jiang and Y. Tong, 2007. Kinetics of ethanol electrooxidation at $\mathrm{Pd}$ electrodeposited on Ti. Electrochem. Commun., 9: 2334-2339. DOI: 10.1016/j.elecom.2007.06.036

Liu, Z., X. Zhang and L. Hong, 2009. Physical and electrochemical characterizations of nanostructured $\mathrm{Pd} / \mathrm{C}$ and $\mathrm{PdNi} / \mathrm{C}$ catalysts for methanol oxidation. Electrochem. Commun., 11: 925-928. DOI: 10.1016/j.elecom.2009.02.030

Nikiforova, T.G., Y.V. Kabeneva and O.A. Runova, 2010. Carbon-supported palladium catalysts for fuel cells. Russ. J. Applied Chem., 83: 1001-1009. DOI: 10.1134/S1070427210060145

Serp, P., M. Corrias and P. Kalck, 2003. Carbon nanotubes and nanofibers in catalysis. Applied Catal. A: General, 253: 337-358. DOI: 10.1016/S0926-860X(03)00549-0

Singh, R.N., A. Singh and Anindita, 2009. Electrocatalytic activity of binary and ternary composite films of Pd, MWCNT and Ni for ethanol electro-oxidation in alkaline solutions. Carbon, 47: 271-278. DOI: 10.1016/j.carbon.2008.10.006

Wang, H., Z. Jusys and R.J. Behm, 2004. Ethanol electrooxidation on a carbon-supported pt catalyst: Reaction Kinetics and product yields. J. Phys. Chem. B., 108: 19413-19424. DOI: 10.1021/jp046561k
Watanabe, K., D. Menzel, N. Nilius and H.J. Freund, 2006. Photochemistry on metal nanoparticles. Chem. Rev., 106: 4301-4320. DOI: 10.1021/cr050167g

Xu, C., L. Cheng, P. Shen and Y. Liu, 2007b. Methanol and ethanol electrooxidation on Pt and Pd supported on carbon microspheres in alkaline media. Electrochem. Commun., 9: 997-1001. DOI: 10.1016/j.elecom.2006.12.003

Xu, C., X. Wang and J. Zhu, 2008. Graphene-metal particle nanocomposites. J. Phys. Chem. C, 112: 19841-19845. DOI: 10.1021/jp807989b

Xu, C.W., H. Wang, P.K. Shen and S.P. Jiang, 2007a. Highly ordered pd nanowire arrays as effective electrocatalysts for ethanol oxidation in direct alcohol fuel cells. Adv. Mater, 19: 4256-4259. DOI: 10.1002/adma.200602911

Yoo, E., T. Okada, T. Kizuka and J. Nakamura, 2008. Effect of carbon substrate materials as a Pt-Ru catalyst support on the performance of direct methanol fuel cells. J. Power Sources, 180: 221-226. DOi: 10.1016/j.jpowsour.2008.01.065

Yu, P., J. Yan, J. Zhang and L. Mao, 2007. Costeffective electrodeposition of platinum nanoparticles with ionic liquid droplet confined onto electrode surface as micro-media. Electrochem. Commun., 9: 1139-1144. DOI: 10.1016/j.elecom.2007.01.022

Zhao, Y., L. Zhan, J. Tian, S. Nie and Z Ning, 2011. Enhanced electrocatalytic oxidation of methanol on $\mathrm{Pd} /$ polypyrrole-graphene in alkaline medium. Electrochim. Acta, 56: 1967-1972. DOI: 10.1016/j.electacta.2010.12.005

Zhao, Y., X. Yang, J. Tian, F. Wang and L. Zhan, 2010. Highly dispersed Pd nanoparticles on 2aminophenoxazin-3-one functionalized MWCNTs surface for methanol electro-oxidation in alkaline media. Mater. Sci. Eng., B, 171: 109-115. DOI: 10.1016/j.mseb.2010.03.082 